Research, Society and Development, v. 9, n. 11, e3889119843, 2020

(CC BY 4.0) | ISSN 2525-3409 | DOI: http://dx.doi.org/10.33448/rsd-v9i11.9843

\title{
Contribuições do pensamento complexo para o conhecimento da enfermagem
} Contributions of complex thought to nursing knowledge

\section{Contribuciones del pensamiento complejo al conocimiento de enfermeira}

Recebido: 02/11/2020 | Revisado: 09/11/2020 | Aceito: 14/11/2020 | Publicado: 19/11/2020

\section{Enéas Rangel Teixeira}

ORCID: https://orcid.org/0000-0002-1721-2056

Universidade Federal Fluminense, Brasil

E-mail: ertteixeira20@gmail.com

Lunna Machado Soares

ORCID: https://orcid.org/0000-0002-2842-6295

Universidade Federal Fluminense, Brasil

E-mail: lunna_machado@hotmail.com

Cristhian Antônio Brezolin

ORCID: https://orcid.org/0000-0002-9525-2459

Universidade Federal Fluminense, Brasil

E-mail: cristhian.brezolin@gmail.com

Juliana da Costa Silva

ORCID: https://orcid.org/0000-0001-5764-6302

Universidade Federal Fluminense, Brasil

E-mail: ju9costa@gmail.com

Clémence Dallaire

ORCID: https://orcid.org/0000-0003-3170-5671

Université Laval, Canadá

E-mail:clemence.dallaire@fsi.ulaval.ca

Patrick Martin

ORCID: https://orcid.org/0000-0003-3966-9257

Université Laval, Canadá

E-mail: patrick.martin@fsi.ulaval.ca

\section{Resumo}

Objetivo: Identificar e discutir as contribuições da adoção do pensamento complexo para o conhecimento de enfermagem. Método: Trata-se de uma revisão integrativa de literatura, que 
abrangeu o período de 2015 a 2020, buscando as palavras-chave "Enfermagem" and "Pensamento Complexo" and "Edgar Morin" nas bases de dados da LILACS e BDENF, sendo selecionados 11 artigos. Resultados: Dentre os resultados, foi construída a categoria adoção e as contribuições do pensamento complexo para o conhecimento da enfermagem. Destaca-se que é preciso a compreensão da complexidade da saúde e lidar com as contradições e incertezas. Isto implica na criação de princípios teóricos e metodológicos articulados com os avanços da enfermagem enquanto ciência e profissão, considerando: a pessoa humana, à ética e o ambiente. Conclusão: A visão linear, determinista e calcada na certeza, precisa ser repensada e a buscar construção de modelos que lide com a complexidade da vida. Isto implica na construção de princípios teóricos articulados com os avanços da enfermagem enquanto ciência e profissão, considerando: a pessoa humana, à ética, o ambiente sujeito às variações entre a ordem, a desordem e a reorganização.

Palavras-chave: Enfermagem; Pensamento complexo; Edgar Morin.

\begin{abstract}
Objective: Identify and discuss the contributions of adopting complex thinking to nursing knowledge. Method: This is an integrative literature review, covering the period from 2015 to 2020, searching for the keywords "Nursing" and "Complex Thinking" and "Edgar Morin" in the LILACS and BDENF databases, with 11 articles selected. Results: Among the results, the adoption category and the contributions of complex thinking to nursing knowledge were built. It is emphasized that it is necessary to understand the complexity of health and deal with contradictions and uncertainties. This implies the creation of theoretical and methodological principles articulated with the advances in nursing as a science and profession, considering: the human person, ethics and the environment. Conclusion: The linear, deterministic vision and based on certainty, needs to be rethought and to seek the construction of models that deal with the complexity of life. This implies the construction of theoretical principles articulated with the advances in nursing as a science and profession, considering: the human person, ethics, the environment subject to variations between order, disorder and reorganization.
\end{abstract}

Keywords: Nursing; Complex thinking; Edgar Morin.

\title{
Resumen
}

Objetivo: Identificar y discutir los aportes de la adopción del pensamiento complejo al conocimiento de enfermería. Método: Se trata de una revisión integradora de la literatura, que abarca el período de 2015 a 2020, buscando las palabras clave "Enfermería" y "Pensamiento 
complejo" y "Edgar Morin" en las bases de datos de LILACS y BDENF, siendo seleccionada 11 artículos. Resultados: Entre los resultados se construyó la categoría de adopción y los aportes del pensamiento complejo al conocimiento de enfermería. Se enfatiza que es necesario comprender la complejidad de la salud y lidiar con las contradicciones e incertidumbres. Esto implica la creación de principios teóricos y metodológicos articulados con los avances de la enfermería como ciencia y profesión, considerando: la persona humana, la ética y el medio ambiente. Conclusión: La mirada lineal, determinista y basada en la certeza, necesita repensarse y buscar construir modelos que aborden la complejidad de la vida. Esto implica la construcción de principios teóricos articulados con los avances de la enfermería como ciencia y profesión, considerando: la persona humana, la ética, el entorno sujeto a variaciones entre orden, desorden y reorganización.

Palabras clave: Enfermería; Pensamiento complejo; Edgar Morin.

\section{Introdução}

O cuidado é uma propriedade humana, que abarca o senso comum, o cultural, o cuidado com as coisas e o profissional. Neste, se destaca o cuidado específico de enfermagem na promoção e na manutenção da vida, oriundo de constructos teóricos, modelos e planejamentos das ações de enfermagem. Portanto, o cuidado de enfermagem é técnico, científico, ético, estético e tem como referências as ciências da vida e humanas, num contexto da saúde que ainda é fragmentado (Copelli, et al., 2016).

Todavia, emergem movimentos intelectuais e sócio culturais em busca de conexão de saberes e práticas, como o pensamento complexo, que é um referencial teórico e filosófico, que pode contribuir para compreensão, reflexão e açõesem diversos campos da enfermagem. De modo que é preciso contextualizar o acontecimento, promover conversas entre as disciplinas e desvelar subjetividades envolvidos na produção de conhecimento e da tecnologia.A adoção do pensamento complexo nesse estudo favorece a compreensão e a produção de conhecimento do cuidado de enfermagem (Cruz, et al., 2017).

O referencial teórico de Edgar Morin, filósofo francês contemporâneo, trata do pensamento complexo como um paradigma da conexão e sistêmico (Morin, 2002, 2005, 2008). O autor propõe uma ciência da conexão de saberes, com a ordem, a desordem e com a incerteza. Esta abordagem não se restringe a um método de investigação específico e nem preconiza métodos que criam recortes e simplificações na produção de conhecimento. 
O conceito de complexidade é diferente de completude, da dificuldade de compreensão e de holismo. Trata-se de um sistema aberto e de troca com o exterior, que se equilibra ese desequilibra, se organiza e se desorganiza num processo perene de adaptação e criação. Os princípios da complexidade são: dialógico; recursão organizacional; holográfico (Morin, 2000). A complexidade é mais um desafio do que uma resposta.

O pensamento complexo apresenta três etapas, as quais auxiliam a compreensão desse estudo. A primeira etapa da complexidade se caracteriza como conhecimentos simples que não ajudam a conhecer as propriedades do conjunto. Na segunda etapa da complexidade, o todo é então menor do que a soma das partes, e na terceira etapa apresenta as dificuldades para nosso entendimento e nossa estrutura mental. O todo é ao mesmo tempo mais e menos do que a soma das partes (Morin, 2011).

A complexidade implica em uma atitude transdisciplinar, ética e estética do cuidado em saúde de modo a criar uma significativa compreensão que possa redimensionar o cuidado em saúde e as conexões relacionais (Santos, Teixeira, \& Cursino, 2017). Neste sentido, a teoria da complexidade é amiúde adotada como referência para pesquisas e ensino de graduação e pós-graduação,

A perspectiva da complexidade possibilita uma compreensão sistêmica do cuidado diante das questões emergentes na saúde, considerando a conexão entre o sujeito, seu contexto social e os serviços de saúde. Há interfaces dos saberes e práticas de enfermagem inerentes ao processo de cuidar, que se constitui complexo, de modo a ser compreendido e desvelado (Morim, 2008)

Diante do exposto, a seguinte pergunta norteadora é elaborada. De que modo o pensamento complexo pode contribuir para o conhecimento da enfermagem? Este estudo tem como objetivo identificar e discutir as contribuições da adoção do pensamento complexo para o conhecimento Enfermagem.

\section{Método}

O conhecimento de enfermagem proposto na temática do estudo foi proveniente de uma revisão integrativa de literatura, portanto foram incluídos artigos de pesquisa originais, reflexões, revisões e excluídos demais tipos de literatura para esse estudo. Os critérios de exclusão do estudo foram artigos que não correspondiam à temática proposta, bem como aqueles que não se enquadravam nas modalidades de estudo previamente determinadas para a elaboração dessa revisão. A revisão integrativa sintetiza achados de estudos com diferentes 
metodologias em uma mesma revisão (Pautasso, Zelmanowicz, Flores, \& Caregnato, 2018), permitindo a procura, a avaliação crítica e a síntese das evidências disponíveis sobre o tema pesquisado.

Esse método segue as seguintes etapas: elaboração da questão de pesquisa; estabelecimento de critérios para inclusão e exclusão de estudos e busca na literatura; definição das informações a serem extraídas dos estudos e coleta de dados; avaliação dos estudos incluídos na revisão integrativa; interpretação dos resultados e apresentação da revisão/síntese.

A pesquisa foi realizada a partir da Biblioteca Virtual em Sáude- BVS usando as palavras-chave "Enfermagem" and "Pensamento Complexo" and "Edgar Morin", no período de 2015 a 2020. Assim foram obtidos 36 artigos. Entretanto, apenas 30 estavam disponíveis. Desses, 15 na Base de dados de enfermagem (BDENF) e 15 na Literatura Latino-Americana e do Caribe em Ciências da Saúde (LILACS). Os referidos estudos foram publicados no Brasil, sendo 24 em língua portuguesa e 6 em língua inglesa. A busca foi realizada no período de janeiro a julho de 2020.

Dos 30 artigos, foram selecionados ao todo 11 que tivessem relação com a enfermagem, pensamento complexo e Edgar Morin para compor este estudo. Diante dos resultados foi construída uma categoria de discussão e reflexão: a adoção e as contribuições do Pensamento complexo para o conhecimento da enfermagem, descrito no quadro dos resultados. A análise escolhida para avaliar os resultados foi a análise descritiva simples, caracterizada pela coleta, descrição e resumo dos dados de um estudo.

\section{Resultados}

Em relação ao ano de publicação dos estudos selecionados, constatou-se um estudo de 2020, um estudo de 2019, um de 2018, três de 2017, três de 2016 e um de 2015. No que tange a modalidade do estudo, todos os artigos elencados são artigos científicos publicados em periódicos nacionais. Os resultados da seleção dos estudos incluídos na revisão integrativa estão apresentados no Quadro 1, contendo seu título, autores, periódicos, ano de publicação e resultados. 
Quadro 1 - A adoção e as contribuições do pensamento complexo para o conhecimento da enfermagem do ano de 2015 a 2020.

\begin{tabular}{|c|c|c|c|c|c|c|c|}
\hline $\begin{array}{l}\text { Numera } \\
\text { ção dos } \\
\text { achados }\end{array}$ & Autor & Título & $\begin{array}{l}\text { Ano/ } \\
\text { Periódico / } \\
\text { Base/Nome } \\
\text { da revista }\end{array}$ & Objetivo & $\begin{array}{l}\text { Sub- } \\
\text { àrea de } \\
\text { conhec } \\
\text { imento }\end{array}$ & $\begin{array}{l}\text { Justificativas para adoção } \\
\text { do Referencial }\end{array}$ & $\begin{array}{l}\text { Contribuições } \\
\text { do Pensamento } \\
\text { Complexo }\end{array}$ \\
\hline Artigo 1 & $\begin{array}{l}\text { Josilaine } \\
\text { Porfírio } \\
\text { da Silva, } \\
\text { Mara } \\
\text { Lucia } \\
\text { Garanha } \\
\text { ni, Aida } \\
\text { Maris } \\
\text { Peres. }\end{array}$ & $\begin{array}{l}\text { Sistem } \\
\text { atizaçã } \\
\text { o da } \\
\text { assistê } \\
\text { ncia de } \\
\text { enferm } \\
\text { agem } \\
\text { na } \\
\text { gradua } \\
\text { ção: } \\
\text { um } \\
\text { olhar } \\
\text { sob o } \\
\text { pensam } \\
\text { ento } \\
\text { comple } \\
\text { xo. }\end{array}$ & $\begin{array}{l}\text { 2015/Scielo } \\
\text { /Rev. } \\
\text { Latino-Am. } \\
\text { Enfermage } \\
\text { m, v.23, n.1 }\end{array}$ & $\begin{array}{l}\text { Analisar } \\
\text { as } \\
\text { percepçõ } \\
\text { es dos } \\
\text { acadêmic } \\
\text { os de um } \\
\text { curso de } \\
\text { graduaçã } \\
\text { o em } \\
\text { enfermag } \\
\text { em sobre } \\
\text { sua } \\
\text { formação } \\
\text { em } \\
\text { Sistemati } \\
\text { zação da } \\
\text { Assistênc } \\
\text { ia de } \\
\text { Enferma } \\
\text { gem }\end{array}$ & $\begin{array}{l}\text { Educaç } \\
\text { ão } \\
\text { (SAE) }\end{array}$ & $\begin{array}{l}\text { A reflexão sobre a formação } \\
\text { da SAE foi fundamentada } \\
\text { nos princípios de Edgar } \\
\text { Morin. Nesta perspectiva, o } \\
\text { tema implica em considerar } \\
\text { o ensino da SAE como um } \\
\text { solo de incertezas, em que o } \\
\text { conhecimento deve estar } \\
\text { enraizado, ser } \\
\text { constantemente regado e } \\
\text { mostrar-se aberto às } \\
\text { transformações. }\end{array}$ & $\begin{array}{lr}\text { A formação em } \\
\text { SAE, sob a } \\
\text { perspectiva do } \\
\text { pensamento } \\
\text { complexo, } \\
\text { proporciona } \\
\text { olhar um } \\
\text { acurado, mais } \\
\text { permitirá que } \\
\text { ensino um } \\
\text { efetivo e crítico, } \\
\text { aplicável às } \\
\begin{array}{lr}\text { demais escolas } \\
\text { de enfermagem. }\end{array}\end{array}$ \\
\hline Artigo 2 & $\begin{array}{l}\text { Thayane } \\
\text { Roberto } \\
\text { Simões } \\
\text { de } \\
\text { Lucca, et } \\
\text { al. }\end{array}$ & $\begin{array}{l}\text { O } \\
\text { signific } \\
\text { ado da } \\
\text { gestão } \\
\text { do } \\
\text { cuidad } \\
\text { o para } \\
\text { docent } \\
\text { es de } \\
\text { enferm } \\
\text { agem } \\
\text { na } \\
\text { ótica } \\
\text { do } \\
\text { pensam } \\
\text { ento } \\
\text { comple } \\
\text { xo. }\end{array}$ & $\begin{array}{l}\text { 2016/Scielo } \\
\text { /Rev } \\
\text { Gaúcha } \\
\text { Enferm; } \\
\text { v.37, n.3 }\end{array}$ & $\begin{array}{l}\text { Compree } \\
\text { nder o } \\
\text { significa } \\
\text { do da } \\
\text { gestão do } \\
\text { cuidado } \\
\text { para } \\
\text { docentes } \\
\text { de } \\
\text { enfermag } \\
\text { em na } \\
\text { ótica do } \\
\text { pensame } \\
\text { nto } \\
\text { complex } \\
\text { o }\end{array}$ & $\begin{array}{l}\text { Ensino } \\
\text { (Gestão } \\
\text { do } \\
\text { cuidado } \\
\text { ) }\end{array}$ & $\begin{array}{l}\text { Diante da prática } \\
\text { fragmentada e da dicotomia, } \\
\text { no ensino e gestão. } \\
\text { Associação entre formação, } \\
\text { currículo e práticas } \\
\text { assistenciais.Diálogo entre o } \\
\text { saber fazer e o cuidar. } \\
\text { "Pensamento Complexo ao } \\
\text { se opor à fragmentação } \\
\text { reducionista, nega a } \\
\text { simplificação e e a } \\
\text { unicausalidade das coisas." }\end{array}$ & 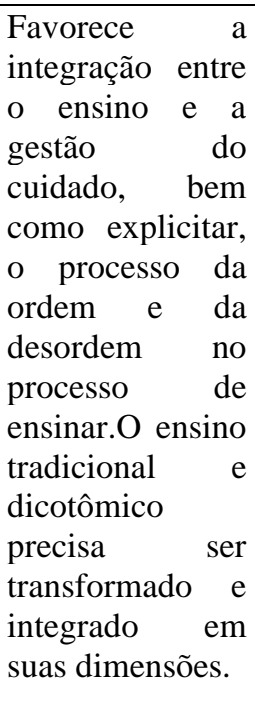 \\
\hline Artigo 3 & $\begin{array}{l}\text { Flávia } \\
\text { Andréia } \\
\text { Pereira } \\
\text { Soares } \\
\text { dos } \\
\text { Santos, } \\
\text { et al. }\end{array}$ & $\begin{array}{l}\text { Integra } \\
\text { lidade } \\
\text { e } \\
\text { atenção } \\
\text { obstétri } \\
\text { ca no } \\
\text { Sistem } \\
\text { a } \\
\text { Único } \\
\text { de } \\
\text { Saúde }\end{array}$ & $\begin{array}{l}\text { 2016/Scielo } \\
\text { /Esc Anna } \\
\text { Nery; v.20, } \\
\text { n.4 }\end{array}$ & $\begin{array}{l}\text { Refletir } \\
\text { sobre a } \\
\text { integralid } \\
\text { ade e } \\
\text { atenção } \\
\text { obstétrica } \\
\text { no } \\
\text { Sistema } \\
\text { Único de } \\
\text { Saúde à } \\
\text { luz da }\end{array}$ & $\begin{array}{l}\text { Enferm } \\
\text { agem } \\
\text { Obstétr } \\
\text { ica }\end{array}$ & $\begin{array}{l}\text { Se faz necessário } \\
\text { compreender a atenção } \\
\text { obstétrica em sua } \\
\text { complexidade, contradições } \\
\text { e incertezas. Para isso, } \\
\text { tomou-se ideias da Teoria da } \\
\text { Complexidade como fios } \\
\text { condutores dessa reflexão, } \\
\text { uma vez que, nessa área da } \\
\text { saúde, faz-se necessário que } \\
\text { as teorias sejam abertas, }\end{array}$ & $\begin{array}{lr}\text { Com o auxílio } \\
\text { da complexidade } \\
\text { é possível buscar } \\
\text { um novo } \\
\text { paradigma } & \text { na } \\
\text { atenção à } & \text { saúde } \\
\text { obstétrica } & \\
\text { centrado } & \text { na } \\
\text { autonomia } & \text { do } \\
\text { usuário } & \\
\text { vinculado } & \text { a }\end{array}$ \\
\hline
\end{tabular}




\begin{tabular}{|c|c|c|c|c|c|c|c|}
\hline & & $\begin{array}{l}\text { (SUS): } \\
\text { reflexã } \\
\text { o à luz } \\
\text { da } \\
\text { teoria } \\
\text { da } \\
\text { comple } \\
\text { xidade } \\
\text { deEdga } \\
\text { r } \\
\text { Morin. }\end{array}$ & & $\begin{array}{l}\text { teoria da } \\
\text { complexi } \\
\text { dade de } \\
\text { Edgar } \\
\text { Morin. }\end{array}$ & & $\begin{array}{l}\text { racionais, } \quad \text { críticas, } \\
\text { reflexivas, autocríticas, } \\
\text { aptas a transformar-se. }\end{array}$ & $\begin{array}{l}\text { humanização e a } \\
\text { ética na } \\
\text { intersubjetividad } \\
\text { e. }\end{array}$ \\
\hline Artigo 4 & $\begin{array}{l}\text { Fernanda } \\
\text { Hannah } \\
\text { da Silva } \\
\text { Copelli, } \\
\text { et al. }\end{array}$ & $\begin{array}{l}\text { O } \\
\text { pensam } \\
\text { ento } \\
\text { comple } \\
\text { xo e } \\
\text { suas } \\
\text { repercu } \\
\text { ssões } \\
\text { na } \\
\text { gestão } \\
\text { em } \\
\text { enferm } \\
\text { agem e } \\
\text { saúde. }\end{array}$ & $\begin{array}{l}\text { 2016/Scielo } \\
\text { /Aquichan, } \\
\text { v.16 n.4 }\end{array}$ & $\begin{array}{l}\text { Evidenci } \\
\text { ar o } \\
\text { conhecim } \\
\text { ento } \\
\text { científico } \\
\text { sobre a } \\
\text { teoria da } \\
\text { complexi } \\
\text { dade nas } \\
\text { publicaçõ } \\
\text { es } \\
\text { científica } \\
\text { s sobre } \\
\text { gestão } \\
\text { em em } \\
\text { enfermag } \\
\text { em e } \\
\text { saúde. }\end{array}$ & $\begin{array}{l}\text { Admini } \\
\text { stração } \\
\text { em } \\
\text { enferm } \\
\text { agem. }\end{array}$ & $\begin{array}{l}\text { Vislumbra-se a } \\
\text { possibilidade de promover a } \\
\text { gestão das práticas em saúde } \\
\text { e enfermagem na } \\
\text { perspectiva do pensamento } \\
\text { complexo.Isso porque a } \\
\text { gestão das práticas em saúde } \\
\text { exige a discussão sobre a } \\
\text { diversidade humana, o } \\
\text { diálogo entre parceiros e } \\
\text { atores sociais, reconhecendo } \\
\text { as igualdades e diferenças } \\
\text { biológicas, sociais, culturais } \\
\text { e políticas. }\end{array}$ & 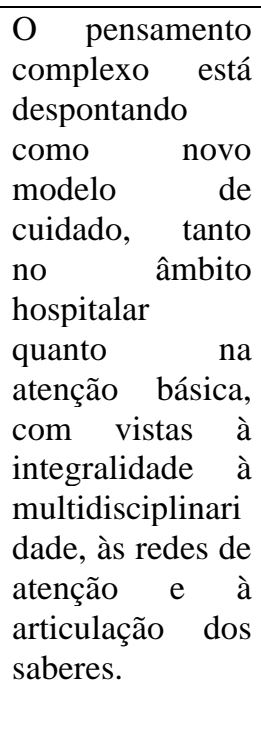 \\
\hline Artigo 5 & $\begin{array}{l}\text { Dirce } \\
\text { Stein } \\
\text { Backes, } \\
\text { et al. }\end{array}$ & $\begin{array}{l}\text { Interati } \\
\text { vidade } \\
\text { sistémi } \\
\text { ca } \\
\text { entre } \\
\text { os } \\
\text { conceit } \\
\text { os } \\
\text { interde } \\
\text { penden } \\
\text { tes de } \\
\text { cuidad } \\
\text { o de } \\
\text { enferm } \\
\text { agem. }\end{array}$ & $\begin{array}{l}2016 / \\
\text { Scielo / } \\
\text { Aquichan, } \\
\text { v. 16, n.1 }\end{array}$ & $\begin{array}{l}\text { Apresent } \\
\text { ar e } \\
\text { discutir a } \\
\text { interativi } \\
\text { dade } \\
\text { sistêmica } \\
\text { entre os } \\
\text { conceitos } \\
\text { interdepe } \\
\text { ndentes } \\
\text { de } \\
\text { cuidado } \\
\text { de } \\
\text { enfermag } \\
\text { em na } \\
\text { perspecti } \\
\text { va dos } \\
\text { pressupo } \\
\text { stos } \\
\text { teóricos } \\
\text { de Edgar } \\
\text { Morin. }\end{array}$ & $\begin{array}{l}\text { Enferm } \\
\text { agem e } \\
\text { filosofi } \\
\text { a. }\end{array}$ & $\begin{array}{l}\text { A necessidade de se } \\
\text { conceber a interatividade } \\
\text { sistêmica entre os conceitos } \\
\text { interdependentes de cuidado } \\
\text { de enfermagem.De outro } \\
\text { modo, é preciso transcender } \\
\text { o saber biomédico para o } \\
\text { alcance do saber } \\
\text { contextualizado, complexo e } \\
\text { sistêmico. }\end{array}$ & $\begin{array}{l}\text { A saúde envolve } \\
\text { modos de ser e } \\
\text { produzir e/ou } \\
\text { recriar a vida em } \\
\text { sua } \\
\text { singularidade e } \\
\text { multidimensiona } \\
\text { lidade. Nessa } \\
\text { perspectiva, } \\
\text { somente } \\
\text { processos } \\
\text { dialógicos } \\
\text { capazes } \\
\text { compreender a } \\
\text { interatividade } \\
\text { sistêmica } \\
\text { potencializar o } \\
\text { viver saudável, } \\
\text { desenvolver de } \\
\text { práticas/ações } \\
\text { empreendedora } \\
\text { para um novo } \\
\text { pensar e agir na } \\
\text { saúde/cuidado } \\
\text { de enfermagem. }\end{array}$ \\
\hline Artigo 6 & $\begin{array}{l}\text { Aline } \\
\text { Cristina } \\
\text { Zerwes } \\
\text { Ferreira, }\end{array}$ & $\begin{array}{l}\text { A } \\
\text { vivênci } \\
\text { a do } \\
\text { portado }\end{array}$ & $\begin{array}{l}2017 / \text { Scielo } \\
/ \quad \text { Texto } \\
\text { Contexto } \\
\text { Enferm; }\end{array}$ & $\begin{array}{l}\text { Conhecer } \\
\text { como o } \\
\text { portador } \\
\text { de }\end{array}$ & $\begin{array}{l}\text { Saúde } \\
\text { Mental }\end{array}$ & $\begin{array}{l}\text { A adoção do psicofármaco } \\
\text { implica por parte do usuário, } \\
\text { numa vivência complexa, } \\
\text { que não se restringe somente }\end{array}$ & $\begin{array}{l}\text { O pensamento } \\
\text { complexo } \\
\text { permite entender } \\
\text { a prática como }\end{array}$ \\
\hline
\end{tabular}




\begin{tabular}{|c|c|c|c|c|c|c|c|}
\hline & et al. & $\begin{array}{l}\mathrm{r} \text { de } \\
\text { transtor } \\
\text { no } \\
\text { mental } \\
\text { no uso } \\
\text { de } \\
\text { psicofá } \\
\text { rmacos } \\
\text { na } \\
\text { perspec } \\
\text { tiva do } \\
\text { pensam } \\
\text { ento } \\
\text { comple } \\
\text { xo. }\end{array}$ & v. 26, n. 3 & $\begin{array}{l}\text { transtorn } \\
\text { o mental } \\
\text { vivencia } \\
\text { o uso de } \\
\text { psicofár } \\
\text { macos }\end{array}$ & & $\begin{array}{l}\text { a explicação farmacológica. } \\
\text { É preciso uma visão } \\
\text { multidimensional } \\
\text { totalidade,de modo que o } \\
\text { pensamento complexo se } \\
\text { adequa nesse estudo. }\end{array}$ & $\begin{array}{l}\text { um processo } \\
\text { dinâmico. } \\
\text { Integra } \\
\text { interconecta na } \\
\text { dialogicidade } \\
\text { vários aspectos } \\
\text { do sujeito: } \\
\text { subjetividade, } \\
\text { aspectos físicos, } \\
\text { trabalho e o } \\
\text { sociocultural. }\end{array}$ \\
\hline Artigo 7 & $\begin{array}{l}\text { Carolliny } \\
\text { Rossi de } \\
\text { Faria } \\
\text { Ichikawa } \\
\text {, et al. }\end{array}$ & $\begin{array}{l}\text { O } \\
\text { cuidad } \\
\text { o à } \\
\text { família } \\
\text { diante } \\
\text { da } \\
\text { perda } \\
\text { neonat } \\
\text { al:uma } \\
\text { reflexã } \\
\text { o sob a } \\
\text { Ótica } \\
\text { da } \\
\text { teoria } \\
\text { da } \\
\text { comple } \\
\text { xidade. }\end{array}$ & $\begin{array}{l}2017 \\
\text { Scielo/ } \\
\text { Revenferm } \\
\text { UFPE } \\
\text { online., } \\
\text { Recife, } \\
11(12)\end{array}$ & $\begin{array}{l}\text { Refletir } \\
\text { sobre o } \\
\text { cuidado à } \\
\text { família } \\
\text { diante da } \\
\text { perda } \\
\text { neonatal. }\end{array}$ & $\begin{array}{l}\text { Enferm } \\
\text { agem } \\
\text { Pediátri } \\
\text { ca. }\end{array}$ & $\begin{array}{l}\text { O cuidado à família que } \\
\text { sofre a perda do filho é } \\
\text { passível de ser abordado por } \\
\text { meio } \\
\text { interdisciplinaridade e da } \\
\text { transdisciplinaridade, como } \\
\text { um cuidado complexo. }\end{array}$ & $\begin{array}{lr}\text { Essa reflexão } \\
\text { teórica } \\
\text { filosófica } \\
\text { aproxima } \\
\text { prática a } \\
\text { cuidado do } \\
\text { família que sofre } \\
\text { uma perda } \\
\text { neonatal com os } \\
\text { pressupostos da } \\
\text { complexidade }\end{array}$ \\
\hline Artigo 8 & $\begin{array}{l}\text { Ronny } \\
\text { Anderso } \\
\mathrm{n} \quad \mathrm{de} \\
\text { Oliveira } \\
\text { Cruz, et } \\
\text { al. }\end{array}$ & $\begin{array}{l}\text { Reflex } \\
\text { ões à } \\
\text { luz da } \\
\text { Teoria } \\
\text { da } \\
\text { Compl } \\
\text { exidad } \\
\text { e e a } \\
\text { formaç } \\
\text { ão do } \\
\text { enferm } \\
\text { eiro. }\end{array}$ & $\begin{array}{l}\text { 2017/ } \\
\text { Scielo } \\
\text { Rev. Bras. } \\
\text { Enferm. } \\
\text { [online]. } \\
2017, \\
\text { vol.70, n.1 }\end{array}$ & $\begin{array}{l}\text { Refletir } \\
\text { sobre a } \\
\text { formação } \\
\text { em } \\
\text { Enferma } \\
\text { gem } \\
\text { levando } \\
\text { em } \\
\text { considera } \\
\text { ção os } \\
\text { princípio } \\
\text { s do } \\
\text { pensar } \\
\text { complex } \\
\text { o } \\
\text { proposto } \\
\text { por } \\
\text { Morin. }\end{array}$ & $\begin{array}{l}\text { Educaç } \\
\text { ão em } \\
\text { Enferm } \\
\text { agem }\end{array}$ & $\begin{array}{l}\text { Na perspectiva de perceber } \\
\text { o cuidar/cuidado pautado } \\
\text { numa visão fragmentada do } \\
\text { ser humano, importam } \\
\text { reflexões no contexto da } \\
\text { formação em Enfermagem } \\
\text { com a finalidade de otimizar } \\
\text { a qualidade de uma } \\
\text { assistência que responda às } \\
\text { necessidades do indivíduo, } \\
\text { considerando-o singular e } \\
\text { plural. }\end{array}$ & $\begin{array}{l}\text { Ao utilizar o } \\
\text { pensamento } \\
\text { complexo, a } \\
\text { religação dos } \\
\text { saberes } \\
\text { disciplinares } \\
\text { compartilhados, } \\
\text { proporciona um } \\
\text { cuidado } \\
\text { ampliado, seguro } \\
\text { e efetivo, } \\
\text { respeitando as } \\
\text { singularidades } \\
\text { dos profissionais } \\
\text { e clientes. }\end{array}$ \\
\hline Artigo 9 & $\begin{array}{l}\text { Antonio } \\
\text { Jorge } \\
\text { Silva } \\
\text { Correa } \\
\text { Júnior, et } \\
\text { al. }\end{array}$ & $\begin{array}{l}\text { Educaç } \\
\text { ão } \\
\text { popular } \\
\text { em } \\
\text { saúde, } \\
\text { pensam } \\
\text { ento } \\
\text { crítico } \\
\end{array}$ & $\begin{array}{l}2018 \\
\text { /Scielo/ } \\
\text { Revenferm } \\
\text { UFPE } \\
\text { online, } \\
12(2)\end{array}$ & $\begin{array}{l}\text { Analisar } \\
\text { sobre a } \\
\text { inserção } \\
\text { do } \\
\text { pensame } \\
\text { nto } \\
\text { crítico e } \\
\text { dos sete }\end{array}$ & $\begin{array}{l}\text { Educaç } \\
\text { ão em } \\
\text { Enferm } \\
\text { agem }\end{array}$ & $\begin{array}{l}\text { O Pensamento Complexo } \\
\text { emparelha-se com a } \\
\text { interdisciplinaridade e auto- } \\
\text { organização preceituadas } \\
\text { pela enfermagem, indo além } \\
\text { do pensamento crítico ao } \\
\text { considerar noções mítico- } \\
\text { simbólicas e racional- }\end{array}$ & $\begin{array}{l}\text { A enfermagem } \\
\text { está envolvida } \\
\text { diretamente no } \\
\text { cuidado } \\
\text { realizado com } \\
\text { cientificidade, e } \\
\text { complexidade. O } \\
\text { entendimento }\end{array}$ \\
\hline
\end{tabular}


(CC BY 4.0) | ISSN 2525-3409 | DOI: http://dx.doi.org/10.33448/rsd-v9i11.9843

\begin{tabular}{|c|c|c|c|c|c|c|c|}
\hline & & $\begin{array}{l}\text { e os } \\
\text { sete } \\
\text { saberes } \\
\text {. }\end{array}$ & & $\begin{array}{l}\text { saberes } \\
\text { na } \\
\text { Educação } \\
\text { Popular } \\
\text { em } \\
\text { Saúde. }\end{array}$ & & $\begin{array}{l}\text { lógico-científicas como } \\
\text { inextrincáveis do cuidado e } \\
\text { das relações de saúde como } \\
\text { fenômenos complexos. }\end{array}$ & $\begin{array}{lr}\text { acerca } & \text { das } \\
\text { formas } & \text { de } \\
\text { articulação } & \\
\text { interdisciplinares } \\
\text { e } \\
\text { transdisciplinare } \\
\text { s dos } r \text { sete } \\
\text { saberes, } \\
\text { como bem } \\
\text { diálogo, faz com } \\
\text { que o objetivo } \\
\text { da EPS reja } \\
\text { atingido. }\end{array}$ \\
\hline Artigo 10 & $\begin{array}{l}\text { Eliabe } \\
\text { Rodrigue } \\
\text { s de } \\
\text { Medeiros } \\
\text {, et al. }\end{array}$ & $\begin{array}{l}\text { Capacit } \\
\text { ação } \\
\text { profissi } \\
\text { onal no } \\
\text { Progra } \\
\text { ma } \\
\text { Saúde } \\
\text { na } \\
\text { Escola } \\
\text { sob a } \\
\text { perspec } \\
\text { tiva da } \\
\text { Teoria } \\
\text { da } \\
\text { Compl } \\
\text { exidad } \\
\text { e. }\end{array}$ & $\begin{array}{l}\text { 2019/Scielo } \\
\text { /Escola } \\
\text { Anna Nery; } \\
\text { v. } 23 \text {, n. } 3\end{array}$ & $\begin{array}{l}\text { Refletir } \\
\text { sobre o } \\
\text { processo } \\
\text { de } \\
\text { capacitaç } \\
\text { ão dos } \\
\text { profissio } \\
\text { nais do } \\
\text { Programa } \\
\text { Saúde na } \\
\text { Escola } \\
\text { mediante } \\
\text { a Teoria } \\
\text { da } \\
\text { Complex } \\
\text { idade }\end{array}$ & $\begin{array}{l}\text { Educaç } \\
\text { ão em } \\
\text { Enferm } \\
\text { agem }\end{array}$ & $\begin{array}{lr}\text { A execução de } & \text { atividades } \\
\text { fragmentadas } & \text { por } \\
\text { profissionais de diferentes } \\
\text { formações e como modelo } \\
\text { simplista de pensamento em } \\
\text { contrapartida } & \text { à } \\
\text { complexidade. } & \text { Por } \\
\text { compreender que muitas } \\
\text { dessas lacunas nas } \\
\text { capacitações do Programa } \\
\text { Saúde na Escola não } \\
\text { conseguem ner } \\
\text { compreendidas pelo modelo } \\
\text { simplista de pensamento. }\end{array}$ & $\begin{array}{l}\text { A interação e o } \\
\text { diálogo entre os } \\
\text { diferentes } \\
\text { profissionais } \\
\text { mediante a união } \\
\text { de ideias } \\
\text { distintas rão } \\
\text { necessários e } \\
\text { torna-se } \\
\text { indissociável } \\
\text { para } \\
\text { complexidade } \\
\text { das capacitações. }\end{array}$ \\
\hline Artigo 11 & $\begin{array}{l}\text { Andréia } \\
\text { Bendine } \\
\text { Gastald, } \\
\text { et al. }\end{array}$ & $\begin{array}{l}\text { Concep } \\
\text { ções } \\
\text { sobre } \\
\text { educaç } \\
\text { ão em } \\
\text { saúde } \\
\text { de } \\
\text { profess } \\
\text { ores e } \\
\text { estudan } \\
\text { tes de } \\
\text { enferm } \\
\text { agem à } \\
\text { luz do } \\
\text { pensam } \\
\text { ento } \\
\text { comple } \\
\text { xo. }\end{array}$ & $\begin{array}{l}\text { 2020/Scielo } \\
\text { / Braz. J. of } \\
\text { Develop; } \\
\text { v.6, n.1 }\end{array}$ & $\begin{array}{l}\text { Analisar } \\
\text { as } \\
\text { concepçõ } \\
\text { es de } \\
\text { educação } \\
\text { em saúde } \\
\text { para } \\
\text { professor } \\
\text { es e } \\
\text { estudante } \\
\text { s de um } \\
\text { currículo } \\
\text { integrado } \\
\text { de } \\
\text { enfermag } \\
\text { em à luz } \\
\text { do } \\
\text { pensame } \\
\text { nto } \\
\text { complex } \\
\text { o. }\end{array}$ & $\begin{array}{l}\text { Educaç } \\
\text { ão em } \\
\text { Enferm } \\
\text { agem }\end{array}$ & $\begin{array}{l}\text { Em virtude da sua não- } \\
\text { linearidade, dinamicidade e } \\
\text { multidimensionalidade, as } \\
\text { reflexões sobre a educação } \\
\text { em saúde, como seiva na } \\
\text { formação do enfermeiro, } \\
\text { fazem eco com as } \\
\text { assertivas do pensamento } \\
\text { complexo de Edgar Morin. }\end{array}$ & $\begin{array}{l}\text { O conceito dos } \\
\text { professores } \\
\text { sobre educação } \\
\text { em saúde } \\
\text { contempla } \\
\text { diferentes } \\
\text { dimensões da } \\
\text { educação } \\
\text { popular em } \\
\text { saúde, que } \\
\text { envolve a } \\
\text { corresponsabiliz } \\
\text { ação } \\
\text { profissionais dos } \\
\text { dos usuários,um } \\
\text { processo, } \\
\text { diálogo,comparti } \\
\text { lhado.Os } \\
\text { conceitos dos } \\
\text { estudantes, ainda } \\
\text { tendem } \\
\text { modelo ao } \\
\text { tradicional. }\end{array}$ \\
\hline
\end{tabular}

Fonte: Elaborada pelos autores (2020). 
Quanto aos tipos de estudos, nos resultados foram encontrados seis artigos de reflexão; quatro de pesquisa original de abordagem qualitativa; um de revisão bibliográfica.

Em relação aos artigos referentes às áreas de conhecimento em enfermagem nos dados encontrados: seis foram educação e ensino na enfermagem; dois na área materno infantil; um de Filosofia e enfermagem; um em Administração de Enfermagem; um em Saúde mental.

\section{Discussão}

Os achados descritos no quadro dos resultados proporcionaram a construção de uma discussão dos dados, onde se fizeram aproximações e confrontos com o referencial da complexidade, buscando a natureza dos estudos e a adoção do Pensamento Complexo nas áreas de conhecimento da enfermagem.

\subsection{A natureza dos estudos}

Quanto aos tipos de estudos, seis dos onze artigos consultados são estudos reflexivos sobre a enfermagem a partir do pensamento complexo. Denota-se assim uma forma de pensar a prática de ensinar, pesquisar e cuidar, voltado para a complexidade da saúde e educação. Sendo uma alternativa ao pensamento clássico dicotômico, fragmentado e simplificado, cuja complexidade se constitui como outra forma de compreensão do contexto da saúde e aponta para ações e atitudes éticas transformadoras, diante da fragmentação do conhecimento.

Os quatro artigos de pesquisa original encontrados no quadro, são de abordagem qualitativa, que se aprofunda nos significados e nos sentidos oriundos dos depoimentos dos integrantes da pesquisa. A visão complexa adequa-se a essa abordagem metodológica e permite discussões dos dados de modo integrado ao contexto do sujeito e contribui para o aprofundamento do conhecimento no que se refere à dimensão relacional e humana no cuidado. Apesar de ser encontrada em estudos qualitativos, a perspectiva complexa, não exclui estudos quantitativos, pois é possível referenciar, tanto estudos qualitativos, quanto quantitativos, desde que não se faça a redução do nível de realidade investigada e nem contribua à fragmentação do conhecimento.

Já o único artigo de revisão escolhido endossa os achados da literatura a fim de corroborar com a interlocução dos mesmos. 


\subsection{Adoção do Pensamento Complexo nas áreas de conhecimento da enfermagem}

Em relação às áreas de conhecimento, os conteúdos das reflexões teóricas e filosóficas apresentados apropriam-se do pensamento completo, de modo que fazem uma relação com o cuidado de enfermagem e a saúde (Backes, et al., 2016). Assim destacam que a ciência pósmoderna tem característica da complexidade, de modo que a enfermagem precisa avançar em relação ao modelo clássico dicotômico para uma visão da integralidade do cuidado, superando o fracionamento do conhecimento. Nesse sentido a transdisciplinaridade, precisa ser considerada aos os diferentes níveis da realidade, a lógica do terceiro incluído e a complexidade (Nicolescu, 2008).

Os autores dos artigos pesquisados se apropriam do pensamento complexo, destacam os princípios teóricos e conceitos operacionais que norteiam esse referencial, tais como: o dialógico; o recursivo e o hologramático. Desse modo, a ordem, a desordem e a reorganização fazem de uma cosmologia que engloba a saúde, a doença e o cuidado com a vida. Essa perspectiva, junto com o princípio da incerteza precisam ser compreendidos nos estudo teóricos e metodológicos, na formação e no ensino da enfermagem. Desse modo a dialogicidade, a interação e a reflexão perene no saber e no fazer, precisam ser apreendidos para o avanço científico, educacional e da tecnologia na enfermagem, como uma ciência da vida e humana em atitudes interdisciplinares e transdisciplinares.

A complexidade é um referencial pautado em conceitos que estão constantemente em processo de construção, sem uma finalização e almeja a religação de saberes, união e disjunção na tentativa de compreender a multidimensionalidade que envolve o cuidado (Barros, Santos, Lunardi, \& Lunardi Filho, 2012).

A adoção do pensamento complexo voltada para área do ensino de enfermagem, destaca a falta de integração no ensino, ausência de diálogo entre as disciplinas num currículo fragmentando, caracterizando a clássica cisão entre a teoria e prática. Nesse sentido, os hiatos, as tendências conservadoras no ensino, a dificuldade de lidar com as incertezas, motivam a buscar um ensino integrado com o contexto da enfermagem, gerando uma formação que gerem conexões de saberes e práticas (Lucca, Vannuchi, Garanhani, Carvalho, \& Pissinati, 2016).

Por conseguinte, o pensamento complexo permite a conexão entre a pesquisa, formação e a assistência. De modo que o currículo precisa ser algo vivo e dinâmico, sujeito a adaptações e reajustes diante das demandas do cotidiano e dos avanços do conhecimento (Correa Júnior, et al., 2018). Nessa perspectiva então, o pensamento complexo, possibilita: 
um ensino dialógico, e a inter-relação entre os saberes e as plurais formas de cuidar; a contextualização, a reflexão, a integração entre o sentir e o pensar no processo da aprendizagem em enfermagem; estimular a criatividade no ensino e na produção de novos conhecimentos.

Em outras palavras, a complexidade favorece a integração entre o cuidado e o ensino, de modo a lidar com a ordem, a desordem e as incertezas no processo de ensinar e aprender. Neste sentido, é preciso pensar transformando, gerando novas possibilidades na maneira de formar pessoas pensantes e criativas (Amim, et al., 2020).

Para produzir uma organização no processo de ensino e aprendizagem é necessário a compreensão da ordem de da desordem como parte inerente da organização social e do planeta. Nessa perspectiva, a formação voltada para a sistematização da assistência de enfermagem, segundo pensamento complexo, favorece um ensino mais efetivo e crítico, aplicável às demais escolas de enfermagem (Silva, Garanhani, \& Guariente, 2015).

Essa abordagem de ensino realça a conexão entre elementos globais, multirreferenciais, que precisam ser considerados na formação do discente. Nesse sentido, a aquisição de conhecimento resulta de um processo de interação entre os docentes, discente e a construção na produção do conhecimento, de modo que é preciso considerar os aspectos cognitivos, afetivos e sociais nesse processo dos saberes e práticas de enfermagem. Urge, portanto, a construção de uma nova cultura de integração em detrimento a visão clássica da desconexão de saberes (Gastald, 2020).

O ensino de graduação, nessa perspectiva, precisa de diálogos entre as disciplinas dos ciclos básicos e profissionais, atendendo as disciplinas das ciências da vida, humanas e socais, bem como as atividades de cuidados diretos, indiretos à pessoa e ao coletivo. Por conseguinte, uma prática interdisciplinar tendendo a transdisciplinaridade se faz necessária na formação do enfermeiro, conforme Santos et al. (2017).

Os achados dos artigos no campo da assistência englobaram a saúde mental, maternoinfantil, a saúde da família e a e educação popular. Ambos voltados para áreas de abrangências do cuidado de enfermagem cujo pensamento complexo veio ao encontro no sentido de compreensão, reflexão e possibilidades de criação de formas de cuidar que sejam coerentes com os níveis de realidades da prática assistencial de enfermagem (Ichikawa, et al., 2017).

De acordo com Copelli et al. (2016), destaca-se que no campo da saúde da mulher, há políticas e programas, que apesar de alguns avanços sociais, ainda não conseguiram romper 
com o paradigma hegemônico, historicamente e socialmente consolidado a enfermagem e saúde.

Os autores apresentam um ponto de vista comum, no sentido se buscar a superar um cuidado dicotômico e fragmentado para a compreensão da complexidade que conecta sujeito, seu corpo e a dimensão sociocultural (Ferreira, Brusamarello, Capistrano, Marin, \& Maftum ,2017). Nessa perspectiva, a visão biologicista, não é suficiente para compreender a pessoa com doença mental, nem mesmo restrição do cuidado ao uso exclusivo de medicamentos, sendo necessária uma visão ampliada.

Conforme Santos et al. (2017), os resultados do estudo se dirigem para um cuidado multidimensional, cuja perspectiva complexa contribui para referência teórica e a construção de práticas que proporcionam bem estar e maior integração entre a equipe de enfermagem e aos clientes. Desse modo, é preciso pensar nas dimensões corporais, culturais, mística, que são simbólicas e intrínsecas aos grupos populacionais especialmente quando se trabalha com a educação popular em saúde. As representações populares em saúde merecem ser discutidas e trabalhadas na avaliação, nos planejamentos estratégicos do cuidado em sua complexidade.

Segundo Copelli et al. (2016), as contribuições voltadas para o campo assistencial ressaltam o papel da visibilidade das inter-relações, a importância das condições ambientais e ecológicas, que podem proporcionar formas mais adequadas de cuidados, de acordo com os níveis de realidade do cliente e dos grupos humanos.

Nesse sentido, a multidimensionalidade do cuidado é ressaltada diante das ações prestadas, considerando a autonomia da pessoa, o ser cidadão, o cuidado humano, a dimensão estética, ética e subjetiva. Isto precisa ser trabalhado na formação do enfermeiro, realizando conexões entre as ciências humanas e da vida, que devem ao tempo todo dialogar na prática os conceitos teóricos de enfermagem e juntos com às ações de cuidados personalizados e discutidos com a família e a comunidade (Medeiros, Feijão, Pinto, \& Santos, 2019).

De modo coadjuvante, a gestão da enfermagem na perspectiva da complexidade precisa considerar as diversidades, a dialogicidade e o contexto, para de fato produzir uma gestão de trabalho com equidade, considerando a dinâmica da instituição. Desse modo, a administração em enfermagem precisa se deslocar da perspectiva do trabalho dividido em tarefas visando exclusivamente a produção, para considerar a organização do serviço de saúde como uma instância viva na qual os trabalhadores sejam vistos como sujeitos do processo do cuidar (Gastald, 2020).

A dimensão subjetiva precisa ser considerada junto com a eficiência do cuidado, lidando com os recursos disponíveis e a imprevisibilidade e a incerteza, de modo que a 
interação humana nesse processo de gestão precisa der uma conquista cotidiana. Trata-se, portanto de uma nova política de gestão, em que o contexto do sujeito seja avaliação e planejamento nas atividades de enfermagem. Em outras palavras, existe um foco de atuação para cuidar, prevenir e promover saúde, que atende a especificidade, competências e parâmetros éticos da profissão, conforme Lucca et al. (2016).

De acordo com Copelli et al. (2016), o pensamento complexo por si mesmo trata da religação dos saberes e essa conexão precisa ocorrer entre os diferentes campos da saúde e suas interfaces; entre o que é científico e o que é popular, de modo que não se trata de uma dispersão de saber, mas focar no cuidado, que não pode ignorar os atravessamentos e as conexões criativas. Por conseguinte, o pensamento complexo está despontando como novo modelo de cuidado, tanto no âmbito hospitalar quanto na atenção básica, com vistas à integralidade, à multidisciplinaridade, às redes de atenção e à articulação dos saberes.

\section{Conclusão}

Adoção da perspectiva teórica da complexidade nos leva a refletir sobre aontologia do ser humano, do enfermeiro e do cuidado que repercute na construção do conhecimento de enfermagem. Ao mesmo tempo, o pensamento complexo distingue-se como uma epistemologia caracterizada como pós-moderna diferente do dualismo cartesiano e do realismo positivista. O pensamento complexo almeja construir um paradigma de conexão em relação ao paradigma da simplificação. Todavia, enfermagem ainda tem uma forte influência do paradigma da simplificação e fragmentação, mas busca avançar seu conhecimento e novos modos de cuidar, ensinar e gerenciar o cuidado.

Desse modo, a visão linear, determinista e calcada na certeza, precisa ser repensada e a buscar construção de modelos que lide com a complexidade da vida. Isto implica na construção de princípios teóricos articulados com os avanços da enfermagem enquanto ciência, arte e profissão, considerando: a pessoa humana, à ética, o ambiente sujeito às variações entre a ordem, a desordem e a reorganização. Essa abordagem aponta a interdisciplinaridade e a transdisciplinaridade como um caminho para a reconstrução de conhecimento no contexto contemporâneo.

Limites do estudo - o trabalho é um revisão integrativa da literatura, nas bases de dados consultadas; instiga por sua vez, a uma revisão sistemática e a uma pesquisa de campo.

Nessa perspectiva, concepções e métodos que comungam com o princípios da complexidade podem ser articuladas para fortalecer a enfermagem, enquanto ciência, arte e 
profissão. Portanto, o paradigma da complexidade não é algo já dado e pronto com respostas para tudo, mas uma proposta de um devir a ser construído diante da fragmentação e dos excessivos "especialismos", complexidade essa que já reflete no cotidiano da enfermagem e aponta à construção de um novo porvir.

\section{Referências}

Amim, E. F., Daher, D. V., Brito, I. S. ., Cursino, E. G., Teixeira, E. R. ., Koopmans, F. F., \& Faria, M. G. de A. (2020). Lifestyle and health promotion of university professors. Research, Society and Development, 9(9), e593997507. doi: https://doi.org/10.33448/rsd-v9i9.7507

Backes, D. S., Zamberlan, C., Colomé, J., Souza, M. T., Marchiori, M. T., Lorenzini E., \& Salazar-Maya, A. M. (2016). Interatividade sistémica entre os conceitos interdependentes de cuidado de enfermagem. Aquichan, 16(1), 24-31. doi: https://dx.doi.org/10.5294/ aqui.2016.16.1.4

Barros, E. J. L., Santos, S. S. C., Lunardi, V. L., \& Lunardi Filho, W. (2012). Ser humano idoso estomizado e ambientes de cuidado: reflexão sob a ótica da complexidade. Revista Brasileira de Enfermagem, 65(5), 844-848. doi: https://dx.doi.org/10.1590/S003471672012000500019

Copelli, F. H. da S., Oliveira, R. J. T., Oliveira, C. M. S., Meirelles, B. H. S., Mello, A. L. S. F., \& Magalhães, A. L. P. (2016). O pensamento complexo e suas repercussões na gestão em enfermagem e saúde. Aquichan, 16(4), 501-512. doi: https://dx.doi.org/10. 5294/aqui.2016.16.4.8

Correa Júnior, A., Souza, T., Sousa, Y., Polaro, S., Santana, M., Silva, S., \& Carvalho, J. (2018). Educação popular em saúde, pensamento crítico e os sete saberes. Revista de Enfermagem UFPE online, 12(2), 537-545. doi: https://doi.org/10.5205/1981-8963v12i2a231062p537-545-2018

Cruz, R. A. de O., Araujo, E. L. M., Nascimento, N. de M., Lima, R. J., França, J. R. F. de S., \& Oliveira, J. dos S. (2017). Reflexões à luz da Teoria da Complexidade e a formação do 
enfermeiro. Revista Brasileira de Enfermagem, 70(1), 236-239. doi: https://doi.org/10.1590/0034-7167-2016-0239

Ferreira, A. C. Z., Brusamarello, T., Capistrano, F. C., Marin, M. J. S., \& Maftum, M. A. (2017). A vivência do portador de transtorno mental no uso de psicofármacos na perspectiva do pensamento complexo. Texto \& Contexto - Enfermagem, 26(3). doi: https://doi.org/10.1590/0104-07072017001000016

Gastaldi, A. B., Garanhani, M. L., Montezeli, J. H., Tacla, M. T. G. M., Guariente, M. H. D. de M., Carvalho, B. G., \& Teixeira, E. Concepções sobre educação em saúde de professores e estudantes de enfermagem à luz do pensamento complexo. Jornal Brasileiro de Desenvolvimento, 6(1),3906-27. doi: https://doi.org/10.34117/bjdv6n1-276

Ichikawa, C., Sampaio, P., de Sá, N., Szylit, R., Santos, S., \& de Vargas, D. (2017). O cuidado à família diante da perda neonatal: uma reflexão sob a ótica da Teoria da Complexidade. Revista de Enfermagem UFPE online, 11(12), 5085-5091. doi: https://doi.org/10.5205/1981-8963-v11i12a22610p5085-5091-2017

Lucca, T. R. S., Vannuchi, M. T. O., Garanhani, M. L., Carvalho, B. G., \& Pissinati, P. de S. C. (2016). O significado da gestão do cuidado para docentes de enfermagem na ótica do pensamento complexo. Revista Gaúcha de Enfermagem, 37(3). doi: https://doi.org/10.1590/1983-1447.2016.03.61097

Medeiros, E. R., Feijão, A. R., Pinto, E. S. G., \& Santos, V. E. P. (2019). Capacitação profissional no Programa Saúde na Escola sob a perspectiva da Teoria da Complexidade. Escola Anna Nery, 23(3). doi: https://doi.org/10.1590/2177-9465-ean-2019-0035

Morin, E. (2000). Ciência com consciência. Rio de Janeiro: Bertrand.

Morin, E. (2002). O Método 5: Humanidade da humanidade. Porto Alegre: Sulina.

Morin, E. (2005). O Método 6: Ética. Porto Alegre: Sulina.

Morin, E. (2008). O método 3. O conhecimento do conhecimento. Porto Alegre: Sulina. 
Morin, E. (2011). Os sete saberes necessários à educação do futuro. São Paulo: UNESCO.

Nicolescu, B. (2008). O manifesto da transdisciplinaridade. São Paulo: TRIOM.

Pautasso, F. F., Zelmanowicz, A. de M., Flores, C. D., \& Caregnato, R. C. A. (2018). Atuação do Nurse Navigator: revisão integrativa. Revista Gaúcha de Enfermagem, 39, 2017-0102. doi: https://doi.org/10.1590/1983-1447.2018.2017-0102

Santos, F. A. P. S., Enders, B. C., Santos, V. E. P., Dantas, D. N. A., \& Miranda, L. S. M. V. (2016). Integralidade e atenção obstétrica no Sistema Único de Saúde (SUS): reflexão à luz da teoria da complexidade de Edgar Morin. Escola Anna Nery, 20(4). doi: https://doi.org/10.5935/1414-8145.20160094

Santos, R., Teixeira, E., \& Cursino, E. (2017). Estudo sobre as relações humanas interpessoais de trabalho entre os profissionais de enfermagem: revisão integrativa. Revista Enfermagem UERJ, 25, e26393. doi:https://doi.org/10.12957/reuerj.2017.26393

Silva, J. P., Garanhan, M. L., \& Guariente, M. H. D. de M. (2015). Sistematização da assistência de enfermagem e o pensamento complexo na formação do enfermeiro: análise documental. Revista Gaúcha de Enfermagem, 35(2),128-34. doi: https://doi.org/10.1590/1983-1447.2014.02.44538

\title{
Porcentagem de contribuição de cada autor no manuscrito
}

\author{
Enéas Rangel Teixeira - 28\% \\ Lunna Machado Soares - 28\% \\ Cristhian Antônio Brezolin - 28\% \\ Juliana da Costa Silva - 10\% \\ Clémence Dallaire - 3\% \\ Patrick Martin - 3\%
}

